\title{
Article \\ Exogenous Gibberellin Treatment Enhances Melatonin Synthesis for Melatonin-Enriched Rice Production
}

\author{
Ok Jin Hwang and Kyoungwhan Back*
}

Citation: Hwang, O.J.; Back, K. Exogenous Gibberellin Treatment Enhances Melatonin Synthesis for Melatonin-Enriched Rice Production. Biomolecules 2022, 12, 198. https:// doi.org/10.3390/biom12020198

Academic Editor: Guzel Kudoyarova

Received: 24 December 2021

Accepted: 21 January 2022

Published: 24 January 2022

Publisher's Note: MDPI stays neutral with regard to jurisdictional claims in published maps and institutional affiliations.

Copyright: (C) 2022 by the authors. Licensee MDPI, Basel, Switzerland. This article is an open access article distributed under the terms and conditions of the Creative Commons Attribution (CC BY) license (https:// creativecommons.org/licenses/by/ $4.0 /)$.
Department of Biotechnology, College of Agriculture and Life Sciences, Chonnam National University, Gwangju 61186, Korea; smilax@chonnam.ac.kr

* Correspondence: kback@chonnam.ac.kr; Tel.: +82-62-530-2165

\begin{abstract}
Melatonin production is induced by many abiotic and biotic stressors; it modulates the levels of many plant hormones and their signaling pathways. This study investigated the effects of plant hormones on melatonin synthesis. Melatonin synthesis in rice seedlings was significantly induced upon exogenous gibberellin $3\left(\mathrm{GA}_{3}\right)$ treatment, while it was severely decreased by GA synthesis inhibitor paclobutrazol. In contrast, abscisic acid (ABA) strongly inhibited melatonin synthesis, whereas its inhibitor norflurazon (NF) induced melatonin synthesis. The observed GAmediated increase in melatonin was closely associated with elevated expression levels of melatonin biosynthetic genes such as TDC3, T5H, and ASMT1; it was also associated with reduced expression levels of catabolic genes $A S D A C$ and $M 2 H$. In a paddy field, the treatment of immature rice seeds with exogenous GA led to enhanced melatonin production in rice seeds; various transgenic rice plants downregulating a GA biosynthesis gene (GA3ox2) and a signaling gene $(G \alpha)$ showed severely decreased melatonin levels, providing in vivo genetic evidence that GA has a positive effect on melatonin synthesis. This is the first study to report that GA is positively involved in melatonin synthesis in plants; GA treatment can be used to produce melatonin-rich seeds, vegetables, and fruits, which are beneficial for human health.
\end{abstract}

Keywords: gibberellins; GA3ox2; G protein alpha; melatonin; RNAi transgenic rice

\section{Introduction}

Melatonin is an indole alkaloid commonly found in plants and animals. In plants, melatonin is involved in normal growth and development, and defense responses against many biotic and abiotic stressors [1,2]. The mode of action of melatonin in plant growth and development is presumably associated with the interactions of various plant hormones, including gibberellins (GAs), ethylene, and brassinosteroids (BRs) [1]. The protective effects of melatonin against multiple adverse environmental (e.g., biotic and abiotic) stresses are attributable to its potent antioxidant and regulatory activities, which induce a vast array of relevant genes [2,3]. A recent study showed that melatonin acts as a signaling molecule in the regulation of starch synthesis during normal growth [4]; it also functions in the regulation of molecular chaperones in response to heat stress [5]. The involvement of melatonin in a diverse array of biological activities strongly suggests that, similar to animals, plants possess melatonin receptors [6]. Although Cand2 was recently proposed as a phytomelatonin receptor [7], its potential phytomelatonin receptor role is controversial [8].

The extremely low levels of melatonin during normal plant growth and development [9] support a role for melatonin as a necessary signaling molecule for phytomelatonin receptor function in plants. For example, rice produces melatonin at a rate of ca. $0.5 \mathrm{ng} / \mathrm{g}$ fresh weight (FW) [10], whereas Arabidopsis and cassava produce melatonin at rates of 0.05 and $0.006 \mathrm{ng} / \mathrm{g} \mathrm{FW}$, respectively $[11,12]$. The low levels of melatonin in plants are consistent with the low enzymatic activities of key melatonin biosynthetic enzymes such as serotonin $\mathrm{N}$-acetyltransferase (SNAT) and $\mathrm{N}$-acetylserotonin $\mathrm{O}$-methyltransferase (ASMT) [13]. However, melatonin is induced in response to many stress conditions; it helps to protect plants 
from stress damage [14,15]. For example, melatonin in rice leaves increased from 0.5 to $225 \mathrm{ng} / \mathrm{g}$ FW upon cadmium challenge [16]. Melatonin affects many plant hormones, including auxin, GA, cytokinins, abscisic acid (ABA), ethylene, salicylic acid, jasmonates, and $B R$ under normal conditions and under various stresses [1]; despite investigations thus far, the role of plant hormones in the regulation of melatonin synthesis remains poorly understood. The effects of melatonin on plant hormones vary among plant species, which suggests complex regulatory networks linking melatonin and plant hormones. As our initial study of the roles of plant hormones in melatonin synthesis, we focused on GA because Arabidopsis thaliana SNAT1 and SNAT2 knockout mutants (snat1 and snat2) showed delayed flowering $[4,17]$ in response to a significant decrease in ent-kaurene synthase (KS), the key gene for GA synthesis [17]. Melatonin treatment increases GA content in some plant species, including cucumber, cotton, rapeseed, apple, and pear [1]. Rice has long been used as a model plant to study melatonin because rice synthesizes melatonin at a rate of up to $0.5 \mathrm{ng} / \mathrm{g} \mathrm{FW}$, which can be easily measured using high-performance liquid chromatography (HPLC), and because melatonin production increases dramatically in response to cadmium treatment. These factors facilitate the investigation of melatonin synthesis in rice plants. The goal of this study was to identify plant hormones that can modulate melatonin synthesis, especially for hormones for inducing melatonin synthesis to produce melatonin-enriched plants or fruits, which are beneficial to human health.

\section{Materials and Methods}

\subsection{Plant Growth Conditions}

Rice (Oryza sativa cv. Dongjin) seeds were sterilized and grown on half-strength Murashige and Skoog medium under cool daylight fluorescent lamps $\left(60 \mu \mathrm{mol} \mathrm{m}{ }^{-2} \mathrm{~s}^{-1}\right.$; Philips, Amsterdam, Netherlands) with a $14 \mathrm{~h}$ light/10 h dark photoperiod $\left(28 / 24^{\circ} \mathrm{C}\right)$. Germinated seeds were transplanted into soil as a field test. The plants were grown in a paddy field at Chonnam National University ( $35^{\circ} 09^{\prime} \mathrm{N}, 126^{\circ} 54^{\prime} \mathrm{W}$; $53 \mathrm{~m}$ a.s.l.), Gwangju, Korea. To investigate the effects of GA on melatonin accumulation in rice seeds, commercially available $\mathrm{GA}_{4+7}$ solution (100 $\mu \mathrm{M}$; Daeyu Co., Ltd., Seoul, Korea) was sprayed with handheld garden sprayer (Kyeyang Co., Cheongju city, Korea) onto immature rice seeds at various time intervals (three applications, once every other day) beginning 1 week after flowering. At 60 days after flowering (DAF) which was about 180 days after sowing, rice seeds were harvested for melatonin quantification. Each treatment was replicated three times.

\subsection{Chemical Treatment}

Seven-day-old rice seedlings in $50 \mathrm{~mL}$ polypropylene conical tubes containing $30 \mathrm{~mL}$ water were rhizospherically pretreated with ABA $(1 \mu \mathrm{M}$; Sigma-Aldrich, St. Louis, MO, USA), norflurazon (10 $\mu \mathrm{M}$; Sigma-Aldrich), GA 3 (10 $\mu \mathrm{M}$; Duchefa Biochemie, Haarlem, The Netherlands), paclobutrazol (10 $\mu \mathrm{M}$; Sigma-Aldrich), or 1\% ethanol (mock control). Pretreatments were applied for $24 \mathrm{~h}$; seedlings were then transferred into new conical tubes containing $0.5 \mathrm{mM} \mathrm{CdCl}_{2}$ for 3 days under continuous light $\left(60 \mu \mathrm{mol}\right.$ photons $\left.\mathrm{m}^{-2} \mathrm{~s}^{-1}\right)$. Leaves and stems were harvested for melatonin quantification.

\subsection{Quantitative Real-Time Polymerase Chain Reaction ( $q P C R$ ) Analysis}

Total RNA of the rice plants was isolated using a NucleoSpin RNA Plant Kit (MachereyNagel, Düren, Germany). First-strand cDNA was synthesized from $2 \mu \mathrm{g}$ of total RNA using MG MMLV Reverse Transcriptase (MGmed, Inc., Seoul, Korea) and an oligo $\mathrm{dT}_{18}$ primer at $42^{\circ} \mathrm{C}$ for $1 \mathrm{~h}$. qPCR was performed in a Mic qPCR Cycler system (Biomolecular Systems, Upper Coomera, QLD, Australia) with specific primers and the Luna Universal qPCR Master Mix (New England Biolabs, Ipswich, MA, USA), as described previously. Gene expression was analyzed using Mic RQ software v2.2 (Biomolecular Systems) and normalized to ACT1. Reverse transcription (RT)-PCR and qPCR were performed using the following primer set: GA3ox2 forward 5'-CTT GAA GAA CCC GCT CTG-3', GA3ox2 
reverse 5'-GAA ACT CCT CCA CAC GTC ACA-3'; G-alpha forward 5'-GAA ACT CCT CCA TCA CGT CAC A-3', G-alpha reverse 5'-CAT CGT CAC GCA TCT CAG-3'; UBQ5 forward 5'-CCG ACT ACA ACA TCC AGA AGG AG-3', UBQ5 reverse 5'-AAC AGG AGC CTA CGC CTA AGC-3'; TDC1 forward 5'-GGC TCA AGC TCT GGA TGG TCA TG-3', TDC1 reverse 5'-GCG AAG TTC CTC GGC ACG AC-3'; TDC2 forward 5'-ATG CCC AGA GTA CCG ACA CC-3' , TDC2 reverse 5'-CCT TAA CCC ATA GCA AGG AAC AA-3'; TDC3 forward 5'-GTG GCT AAA ACA TCT CGG TAG G-3', TDC3 reverse 5'-GCA GGA TTA TTT TGC CGT GTC-3'; T5H forward 5'-CCT CGT CCT GGA CAT GTT CGT C-3', T5H reverse 5'-ATG GCG AAC GTG TTG ATG AAC AC-3'; SNAT1 forward 5'-CAG TAG AGC CAC CAT CAG CA-3', SNAT1 reverse 5'-ATC CCA CCT TGT CGC ATA AA-3 ${ }^{\prime}$; SNAT2 forward 5'-GTC TGG GAC GTG GTC GTG-3', SNAT2 reverse 5'-GTT GCC TTG AGC GGT AGA AG-3'; COMT forward 5'-CCT GCT CGC CTC CTA CAA-3', COMT reverse 5'-ATG CCC TCG TTG AAG ACG-3'; ASMT1 forward 5'-GCC AAG GCT CCC AGT AAC AA-3', ASMT1 reverse 5'-CCT TTC CTC CAG CAT CCC TC-3'; ASDAC forward 5'-ATG GAA CAG CTG TGG G-3', ASDAC reverse 5'-ACC ACG ATG CTT CGA AGT-3'; $M 2 H$ forward 5'-ACT AGT ATG CCC GCC GTG GCC-3', $M 2 H$ reverse 5'-GAG CTC GTG TCG TAC CTG-3'; $M 3 H$ forward 5'-ACT AGT ATG GCG GGA GCA AGA-3', $M 3 H$ reverse 5'-GAG CTC GCT TTT AGT CTC TGA-3'; and ACT1 forward 5'-TGC TAT GTA CGT CGC CAT CCAG-3', ACT1 reverse 5'-AAT GAG TAA CCA CGC TCC GTCAA-3'.

\subsection{Quantification of Serotonin, N-Acetylserotonin, and Melatonin}

Frozen samples $(0.1 \mathrm{~g})$ were pulverized into a powder in liquid nitrogen using the TissueLyser II (Qiagen, Tokyo, Japan) and then extracted with $1 \mathrm{~mL}$ methanol for serotonin and $N$-acetylserotonin quantification, and with $1 \mathrm{~mL}$ chloroform for melatonin quantification. Prior to serotonin and $N$-acetylserotonin measurements, methanol extracts were centrifuged for $10 \mathrm{~min}$ at $12,000 \times g$; supernatants $(10 \mu \mathrm{L})$ were subjected to HPLC using a fluorescence detector system (Waters, Milford, MA, USA). Prior to melatonin measurement, chloroform extracts were centrifuged for $10 \mathrm{~min}$ at $12,000 \times g$, and resulting supernatants $(200 \mu \mathrm{L})$ were completely evaporated and dissolved in $0.1 \mathrm{~mL}$ of $40 \%$ methanol; $10 \mu \mathrm{L}$ aliquots were subjected to HPLC using a fluorescence detector system (Waters), as described previously [16]. All measurements were performed in triplicate.

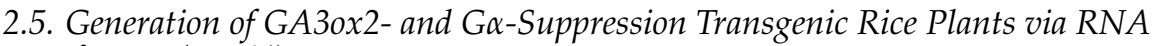 Interference (RNAi)}

The pTCK303 binary vector was used to suppress either the GA3ox2 (GenBank accession number Os01g0177400) or $G \alpha$ rice gene (GenBank accession no. D38232), as previously described [18]. Briefly, an N-terminal 130 bp GA3ox2 cDNA fragment was amplified by RT-PCR using the following primer set: GA3ox2-F $5^{\prime}$-ACT AGT TCC TCC TTC TTC TCC AAG-3' (SpeI site underlined) and GA3ox2-R 5'-GAG CTC AAA CTC CTC CAT CAC GTC ACA-3' (SacI site underlined) with the cDNA templates synthesized from total RNA from rice seedlings. For $G \alpha$, a C-terminal 267-bp $G \alpha$ cDNA fragment was amplified using the following primer set: $G \alpha-F 5^{\prime}$-ACT AGT AGC GAA TAT GAT CAG ATG CTA-3' (SpeI site underlined) and $G \alpha-R 5^{\prime}$-GAG CTC TTC AAA CTT CTT CTT GAC-3' (SacI site underlined). Both PCR products were subcloned into the $\mathrm{T}$ and $\mathrm{A}$ cloning vector ( $\mathrm{T}$ and A:GA3ox2 and $\mathrm{T}$ and $\mathrm{A}: \mathrm{G} \alpha$; RBC Bioscience, New Taipei City, Taiwan) prior to additional cloning procedures. From both T and A:GA3ox2 and T and A:G $\alpha$ plasmids, the antisense GA3ox2 and $G \alpha$ inserts were prepared by $S a c I$ and $S p e I$ double digestion; sense GA3ox2 and $G \alpha$ inserts were prepared by KpnI and BamHI double digestion. The antisense fragments were first ligated into the pTCK303 vector, followed by the sense fragments of both inserts. The resulting pTCK303:GA3ox2 and pTCK303:G $\alpha$ RNAi binary vectors were independently transformed into Agrobacterium tumefaciens LBA4404; Agrobacterium-mediated rice transformation was performed using embryogenic calli derived from $O$. sativa cv. Dongjin rice seeds, as previously described [8,19]. 


\subsection{Statistical Analyses}

All data were analyzed using analysis of variance (ANOVA) with IBM SPSS Statistics 23 software (IBM Corp., Armonk, NY, USA). Means with different letters or asterisks indicate significantly different values evaluated using $p$ values $<0.05$, according to the least significant difference test or Tukey's post hoc honest significant difference (HSD) test. All data are presented as means \pm standard deviations.

\section{Results}

\subsection{GA Pretreatment Increases Melatonin Synthesis in Response to Cadmium}

To examine the effects of GA on melatonin synthesis, 7-day-old rice seedlings were rhizospherically pretreated $\mathrm{GA}_{3}$, followed by cadmium treatment to induce melatonin induction. A GA concentration of $10 \mu \mathrm{M} \mathrm{GA}$ is commonly used in GA assays for germination and third leaf sheath elongation tests [20]. Melatonin was produced at rates of ca. $76 \mathrm{ng} / \mathrm{g}$ FW by mock control rice seedlings and $125 \mathrm{ng} / \mathrm{g}$ FW by $\mathrm{GA}_{3}$-pretreated rice seedlings, representing a 1.8-fold difference (Figure 1). In contrast, pretreatment with $10 \mu \mathrm{M}$ of paclobutrazol, a GA biosynthesis inhibitor, sharply inhibited cadmium-induced melatonin synthesis, such that rice seedlings produced threefold less melatonin than the mock control did ( $25 \mathrm{ng} / \mathrm{g} \mathrm{FW}$ ); this indicated the involvement of GA in cadmium-induced melatonin biosynthesis. In sharp contrast, ABA pretreatment $(1 \mu \mathrm{M})$ resulted in the lowest melatonin production ( $12 \mathrm{ng} / \mathrm{g} \mathrm{FW})$, sixfold less than that of the mock control. To confirm an inhibitory effect of ABA on melatonin synthesis, rice seedlings were pretreated with the ABA biosynthesis inhibitor norflurazon and challenged with cadmium. Rice seedlings pretreated with $10 \mu \mathrm{M}$ norflurazon exhibited the highest melatonin production $(160 \mathrm{ng} / \mathrm{g}$ FW), indicating that ABA is a potent melatonin synthesis inhibitor. In summary, GA is a potent melatonin synthesis inducer, whereas $\mathrm{ABA}$ is a potent melatonin synthesis inhibitor.

(A)

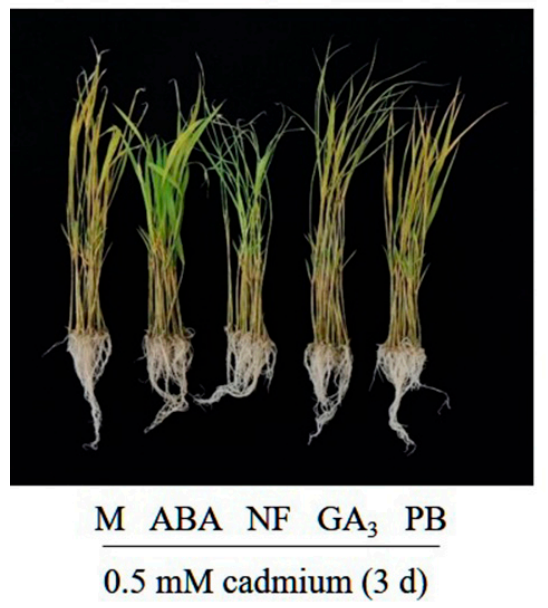

(B)

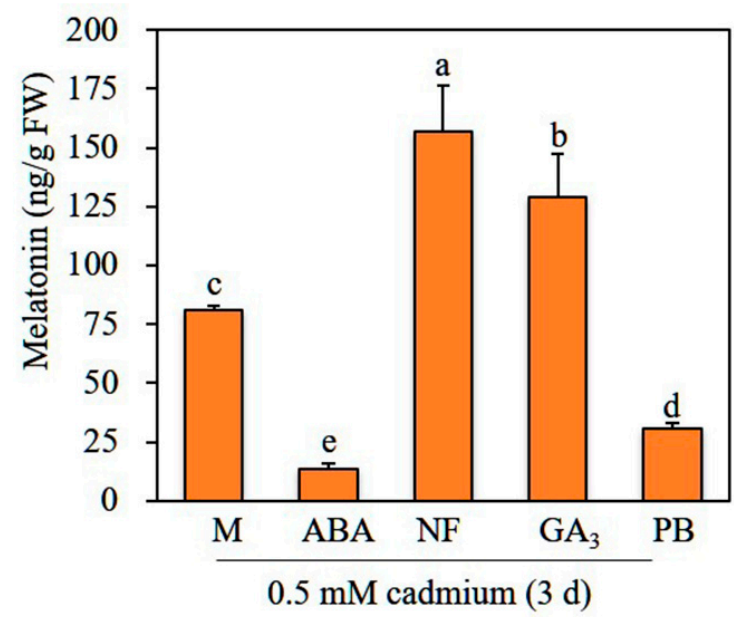

Figure 1. Melatonin content in response to plant hormones. (A) Phenotypes of 7-day-old rice seedlings after hormone and cadmium treatments. (B) Melatonin content. Seven-day-old rice seedlings rhizospherically treated with various hormones independently for $24 \mathrm{~h}$, then treated with $0.5 \mathrm{mM}$ cadmium for 3 days. Different letters indicate significant differences $(p<0.05$; analysis of variance (ANOVA), followed by Tukey's honest significant difference (HSD) post hoc tests). M, water containing $0.1 \%$ ethanol; ABA, $1 \mu \mathrm{M}$ abscisic acid; NF, $10 \mu \mathrm{M}$ norflurazon; $\mathrm{GA}_{3}, 10 \mu \mathrm{M}$ gibberellic acid 3; $\mathrm{PB}, 10 \mu \mathrm{M}$ paclobutrazol.

\subsection{GA Dose-Dependent Melatonin Production}

To determine the optimal $\mathrm{GA}_{3}$ concentration for melatonin induction, we pretreated 7-day-old rice seedlings with various concentrations of $\mathrm{GA}_{3}(0.1-100 \mu \mathrm{M})$ for $24 \mathrm{~h}$. The resulting seedlings were challenged with cadmium for 3 days. We observed a GA dose- 
dependent increase in melatonin production (Figure 2A). Even in the $0.1 \mu \mathrm{M} \mathrm{GA}_{3}$ pretreatment, melatonin synthesis was significantly increased, with a peak of $180 \mathrm{ng} / \mathrm{g} \mathrm{FW}$ melatonin in the $100 \mu \mathrm{M} \mathrm{GA}_{3}$ treatment. In contrast, paclobutrazol treatment $(10 \mu \mathrm{M})$ inhibited melatonin induction. Norflurazon treatment showed no dose-dependent increase in melatonin (Figure 2B); melatonin synthesis increased, peaked, and decreased at norflurazon treatment levels of 1,10 , and $50 \mu \mathrm{M}$, respectively. At a $100 \mu \mathrm{M}$ dose of norflurazon, melatonin synthesis was comparable with synthesis in the mock control. These adverse effects of high norflurazon concentration on melatonin synthesis may be ascribed to its inhibition of carotenoid biosynthesis, a key pigment for photosynthesis [21,22]. Because melatonin induction under cadmium treatment requires light and its receptor phytochrome [23], pigment disruption appears to inhibit light absorption that is essential to melatonin induction.

(A)

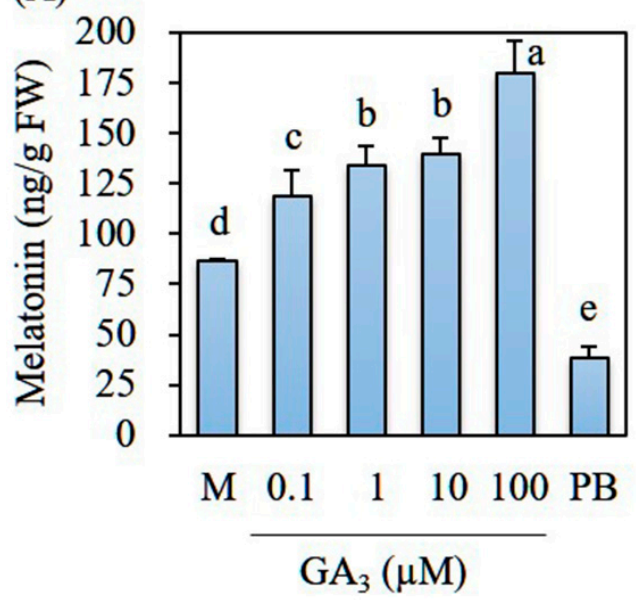

(B)

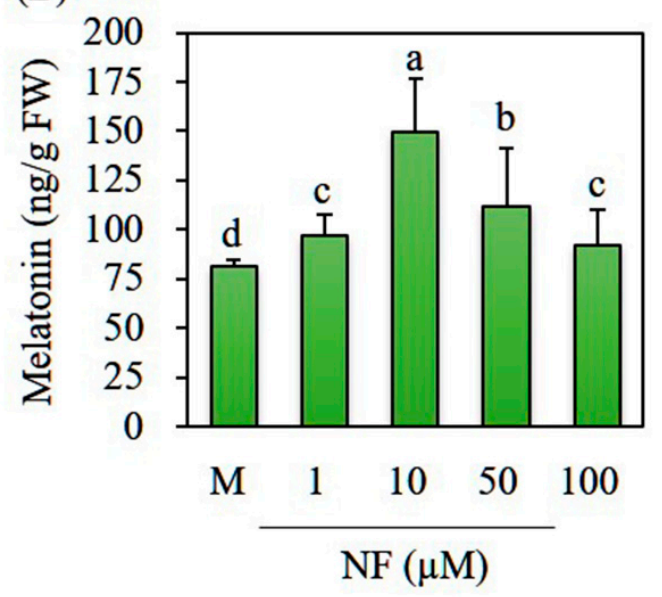

Figure 2. Dose-dependent melatonin levels in response to (A) $\mathrm{GA}_{3}$ and (B) norflurazon. Various concentrations of $\mathrm{GA}_{3}$ or NF were used to rhizospherically treat to 7-day-old rice seedlings for $24 \mathrm{~h}$, followed by treatment with $0.5 \mathrm{mM}$ cadmium for 3 days. Melatonin content was quantified using high-performance liquid chromatography (HPLC). Different letters denote significant differences ( $p<0.05$; ANOVA, followed by Tukey's HSD post hoc tests). M, water containing $0.1 \%$ ethanol; GA 3 , gibberellic acid 3; PB, pachlobutrazol; NF, norflurazon.

\subsection{Increased Melatonin Production in Rice Seedlings and Seeds after GA Treatment in the Absence of Cadmium Treatment}

To investigate whether GA treatment enhances melatonin production in rice seedlings and rice seeds in the absence of cadmium treatment, we rhizospherically treated 7-day-old rice seedlings with various concentrations of $\mathrm{GA}_{3}$ for $24 \mathrm{~h}$ and then performed melatonin quantification. Leaves of the mock control produced $0.25 \mathrm{ng} / \mathrm{g}$ FW melatonin, whereas $1 \mu \mathrm{M} \mathrm{GA}_{3}$-treated leaves produced melatonin at a rate of $0.55 \mathrm{ng} / \mathrm{g} \mathrm{FW}$ (Figure 3A). A dose-dependent increase in melatonin production was not observed under increasing $\mathrm{GA}_{3}$ concentrations, in contrast to our results for cadmium-treated leaves (Figure 2A). To determine whether GA treatment could also induce melatonin production in seeds, we sprayed immature rice seeds grown in the paddy field with $100 \mu \mathrm{M} \mathrm{GA}_{4+7}$, beginning at $7 \mathrm{DAF}$, at various time intervals. At $60 \mathrm{DAF}$, rice seeds were harvested for melatonin quantification. Untreated control rice seeds contained $0.35 \mathrm{ng}$ melatonin/g rough seed, whereas GA-treated seeds at $7 \mathrm{DAF}$ contained $0.67 \mathrm{ng}$ melatonin/g rough seed; this represented a nearly twofold increase (Figure 3B). Melatonin levels gradually decreased in rice seeds when GA was supplied later than 7 DAF. Among husked (brown) rice seed, control rice seeds contained $0.07 \mathrm{ng}$ melatonin/g brown seed, whereas GA-treated rice seeds produced $0.14 \mathrm{ng}$ melatonin/g brown seed; this represented a twofold increase. Collectively, these data indicate that GA elicits melatonin synthesis in both leaves and seeds of rice plants. 
(A)

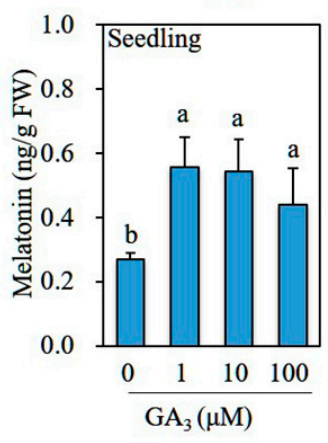

(B)

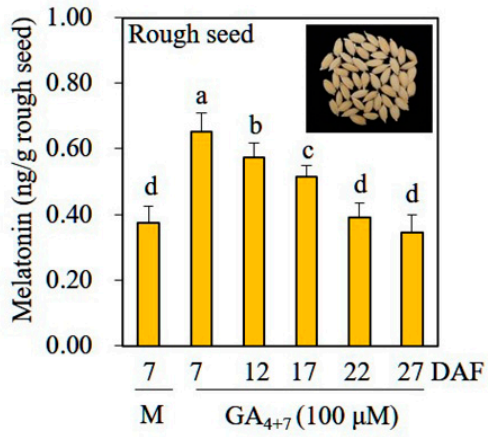

(C)

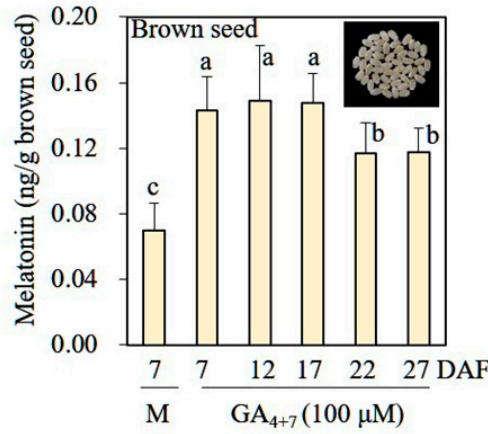

Figure 3. Melatonin levels in (A) rice seedlings, (B) rough seeds, and (C) brown seeds after treatment with GA in the absence of cadmium treatment. Seven-day-old rice seedlings were treated with various concentrations of $\mathrm{GA}_{3}$ for $24 \mathrm{~h}$; leaves or seeds were subjected to HPLC quantification of melatonin. In addition, immature rice seeds were treated at various time intervals with $100 \mu \mathrm{M}$ of commercially available $\mathrm{GA}_{4+7}$ (Daeyu Co., Ltd.) three times every other day in the field. After 60 days after flowering (DAF), rice seeds were harvested for melatonin quantification. Different letters denote significant differences ( $p<0.05$; ANOVA, followed by Tukey's HSD post hoc tests). M, water containing $0.1 \%$ ethanol; $\mathrm{GA}_{3}$, gibberellic acid 3 .

\subsection{Characterization of Genes Involved in Melatonin Biosynthesis and Catabolism in Response to GA Treatment}

Seven-day-old rice seedlings were challenged with $10 \mu \mathrm{MGA}_{3}$ for $12 \mathrm{~h}$; their meristematic tissues were separated and harvested for total RNA extraction (Figure 4B). To determine whether $\mathrm{GA}_{3}$ treatment altered the expression of genes responsible for melatonin synthesis and degradation, we performed qPCR gene expression analysis using ACT1 as a reference gene (Figure 4A). Expression levels of melatonin biosynthetic genes tryptophan decarboxylase 3 (TDC3), tryptamine 5-hydroxylase (T5H), and $\mathrm{N}$-acetylserotonin $\mathrm{O}$-methyltransferase 1 (ASMT1) were elevated by $\mathrm{GA}_{3}$ treatment; expression levels of the biosynthetic genes TDC1, SNAT1, SNAT2, and caffeic acid O-methyltransferase (COMT) were downregulated (Figure 4C). SNAT1 and SNAT2 were downregulated in melatonin-treated rice seedlings, suggesting feedback regulation upon melatonin response [24]. Among catabolic genes, $\mathrm{GA}_{3}$ treatment inhibited the expression of $N$-acetylserotonin deacetylase (ASDAC) and melatonin 2-hydroxylase $(\mathrm{M} 2 \mathrm{H})$, whereas the expression of melatonin 3-hydroxylase $(\mathrm{M} 3 \mathrm{H})$ was not altered; the suppression of these two catabolic genes presumably facilitated melatonin production under $\mathrm{GA}_{3}$ treatment compared with the mock control. Because GA action occurs in meristem tissues, we applied qPCR analysis to meristematic tissues [25]. The expression profiles of genes related to melatonin biosynthesis and catabolism in rice upper leaves were not significantly altered in response to $\mathrm{GA}_{3}$ treatment (data not shown).

\subsection{Decreased Melatonin Production in Transgenic Rice Plants Downregulating the GA Biosynthetic Gene GA3ox2}

To verify the involvement of GA in melatonin production in vivo, we generated transgenic rice plants downregulating the key GA biosynthetic gene GA3-oxidase 2 (GA3ox2), which catalyzes inactive $\mathrm{GA}_{9} / \mathrm{GA}_{20}$ into active $\mathrm{GA}_{4} / \mathrm{GA}_{1}$. Its knockout mutant, $D 18$, is deficient in $\mathrm{GA}_{1}$ and has a dwarf phenotype [26]. Three independent homozygous transgenic RNAi lines downregulating rice GA3ox2 were generated; the resulting GA3ox2 RNAi lines showed semidwarf phenotypes (Figure 5A,C), whereas seed phenotypes of the GA3ox2 RNAi lines were similar to the seed phenotypes of wild-type (WT) plants (Figure 5D). These phenotypic features were similar to the features of $d 18$ mutant rice [26]. GA3ox2 mRNA levels were suppressed in three independent GA3ox2 RNAi lines compared with the levels in the nontransgenic WT (Figure 5E). When these GA3ox2 RNAi seedlings had been challenged with cadmium to induce melatonin production, WT produced $75 \mathrm{ng} / \mathrm{g}$ FW melatonin, whereas these RNAi lines produced threefold lower melatonin than that of the 
WT (Figure 5F). In the absence of cadmium treatment, WT rice produced about $0.3 \mathrm{ng} / \mathrm{g}$ FW melatonin, whereas GA3ox2 RNAi lines produced half of the melatonin quantity in WT seedlings (data not shown). These data indicate that endogenous GA levels are functionally coupled to melatonin production as a positive melatonin synthesis-inducing factor.

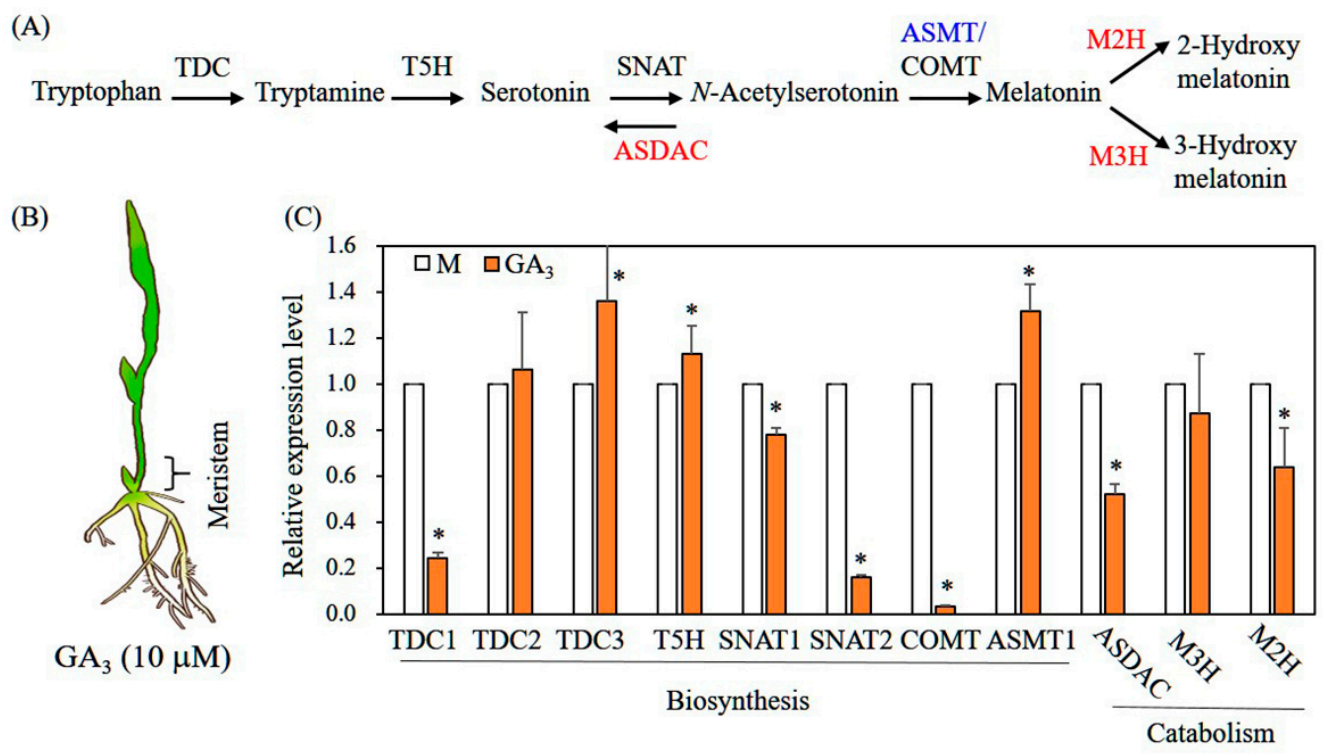

Figure 4. Expression levels of transcripts encoding melatonin biosynthetic and catabolic genes. (A) Genes involved in melatonin biosynthesis and catabolism in plants. (B) Schematic representation of rice seedlings treated with $\mathrm{GA}_{3}$ and the apical meristem region. (C) Quantitative reversetranscription polymerase chain reaction ( $\mathrm{qPCR}$ ) analysis of various genes involved in melatonin synthesis and catabolism. Asterisks $\left(^{*}\right)$ denote significant differences from the mock control (M) ( $p<0.05$; ANOVA, followed by Tukey's HSD post hoc tests). TDC1, tryptophan decarboxylase 1 (AK069031); TDC2 (AK103253); TDC3 (Os08g0140500); T5H, tryptamine 5-hydroxylase (AK071599); SNAT1, serotonin N-acetyltransferase 1 (AK059369); SNAT2 (AK068156); COMT, caffeic acid Omethyltransferase (AK064768); ASMT1, N-acetylserotonin O-methyltransferase (AK072740); ASDAC, $\mathrm{N}$-acetylserotonin deacetylase (AK072557); $\mathrm{M} 3 \mathrm{H}$, melatonin 3-hydroxylase (AK067086); $\mathrm{M} 2 \mathrm{H}$, melatonin 2-hydroxylase (AK119413); ACT1, actin 1 (Os03g50885).

\subsection{Decreased Melatonin Production in Transgenic Rice Plants Downregulating G-Protein Alpha $(G \alpha)$}

$G \alpha$ participates in a key GA signaling component; its mutant rice $d 1$ produces round dwarf grains $[27,28]$. To determine whether transgenic rice suppressing $G \alpha$ exhibits less melatonin synthesis than that of its WT counterpart, we generated rice G $\alpha$ RNAi transgenic lines. As observed in $G \alpha$ mutant rice (d1) plants [28,29], $G \alpha$ RNAi plants exhibited typical phenotypes characterized by round dwarf seeds (Figure 6A-E). When these G $\alpha$ RNAi rice seedlings had been challenged with cadmium to induce melatonin production, four independent homozygous $G \alpha$ RNAi rice seedlings produced melatonin at mean of $20 \mathrm{ng} / \mathrm{g}$ FW, which was threefold less than the quantity produced by WT seedlings, indicating a positive effect of GA on melatonin production (Figure 6F). However, the $\mathrm{GA}_{3}$-induced melatonin increase was not abolished in these $G \alpha$ RNAi rice seedlings compared with WT seedlings (Figure 7A,D). This result for $G \alpha$ RNAi rice seedlings was similar to the phenotype of $d 1$ mutant rice, which does not completely lose GA sensitivity, suggesting the presence of a $G \alpha$-independent GA pathway [29]. In contrast, the induction of melatonin biosynthetic precursors serotonin but not $N$-acetylserotonin was abolished in these $G \alpha$ RNAi rice seedlings by GA treatment; these precursors were induced in a similar pattern to melatonin induction upon GA treatment in WT seedlings (Figure 7B,C). The increase in serotonin is presumably attributable to the enhanced expression of TDC3 upon GA treatment in WT seedlings; the increase in melatonin may have resulted from the combined 
effects of increased TDC3 expression and decreased expression of catabolic genes such as ASDAC and $M 2 H$.

(A)

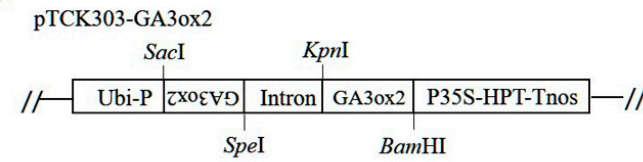

(B)

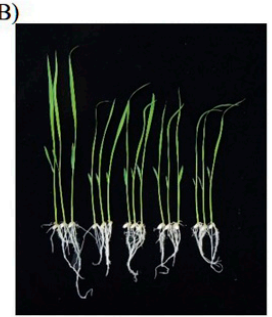

WT $\frac{3 \quad 4 \quad 5 \quad 8}{\text { GA3ox2 }}$ RNAi

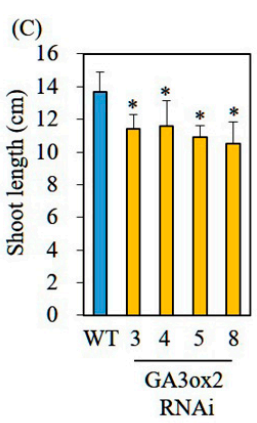

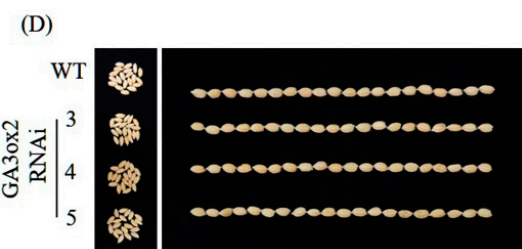
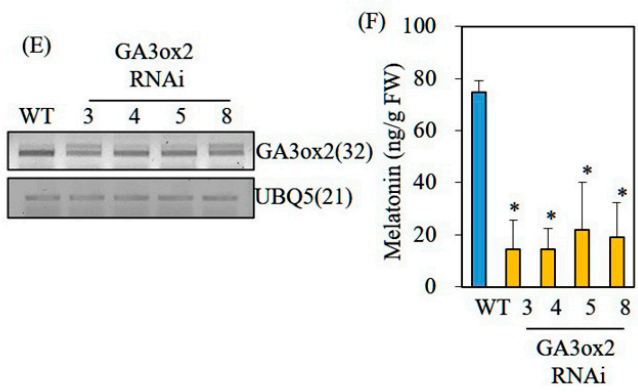

Figure 5. Structure of binary vector pTCK303-GA3ox2 and the generation of GA3ox2-suppressed transgenic rice plants. (A) Schematic diagram of the pTCK303:GA3ox2 binary vector. (B) Seven-dayold rice seedling phenotypes of wild-type (WT) and GA3ox2 RNAi transgenic rice $\left(\mathrm{T}_{2}\right)$. (C) Shoot length measurement. (D) Seed phenotype. (E) RT-PCR analysis results for WT and $\mathrm{T}_{2}$ lines. (F) Melatonin levels of WT and transgenic lines. Seven-day-old rice seedlings challenged with $0.5 \mathrm{mM}$ cadmium for 3 days, then subjected to melatonin quantification. Asterisks $\left.{ }^{*}\right)$ indicate significant differences from the WT ( $p<0.05$; ANOVA, followed by Tukey's HSD post hoc tests). Numbers in parentheses indicate numbers of PCR cycles. GenBank accession numbers: Os01g0177400 (GA3ox2) and Os03g13170 (UBQ5). Ubi-P, maize ubiquitin promoter; P35S, 35 S cauliflower mosaic virus 35S promoter; HPT, hygromycin phosphotransferase; Tnos, nopaline synthase terminator.

(A)

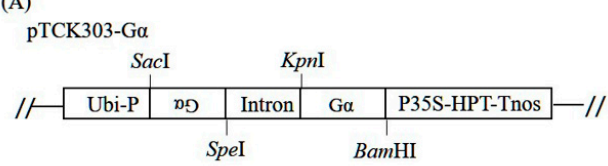

(B)

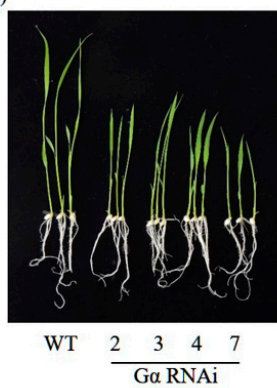

(C)

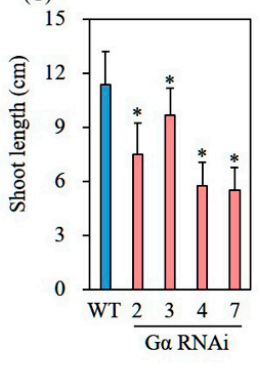

$\mathrm{E}$

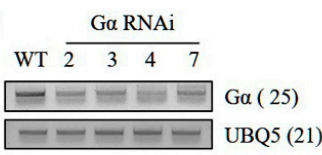

Figure 6. Structure of binary vector pTCK303-G $\alpha$ and generation of $G \alpha$-suppressed transgenic rice plants. (A) Schematic diagram of pTCK303:G $\alpha$ binary vector. (B) Seven-day-old rice seedling phenotypes of WT and $G \alpha$ RNAi transgenic rice $\left(\mathrm{T}_{2}\right)$. (C) Shoot length measurement. (D) Seed phenotype. (E) RT-PCR analysis results for WT and $\mathrm{T}_{2}$ lines. (F) Melatonin levels of WT and $\mathrm{T}_{2}$ lines. Seven-day-old rice seedlings challenged with $0.5 \mathrm{mM}$ cadmium for 3 days and then subjected to melatonin quantification. Asterisks $\left(^{*}\right)$ indicate significant differences from WT $(p<0.05$; ANOVA, followed by Tukey's HSD post hoc tests). Numbers in parentheses indicate the numbers of PCR

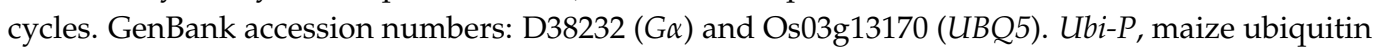
promoter; $P 35 S$, $35 \mathrm{~S}$ cauliflower mosaic virus $35 \mathrm{~S}$ promoter; $H P T$, hygromycin phosphotransferase; Tnos, nopaline synthase terminator. 
(A)

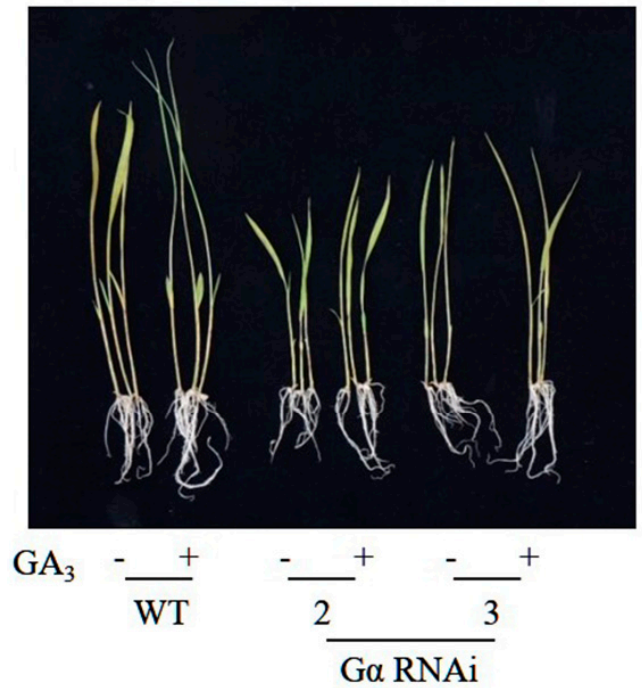

(B)

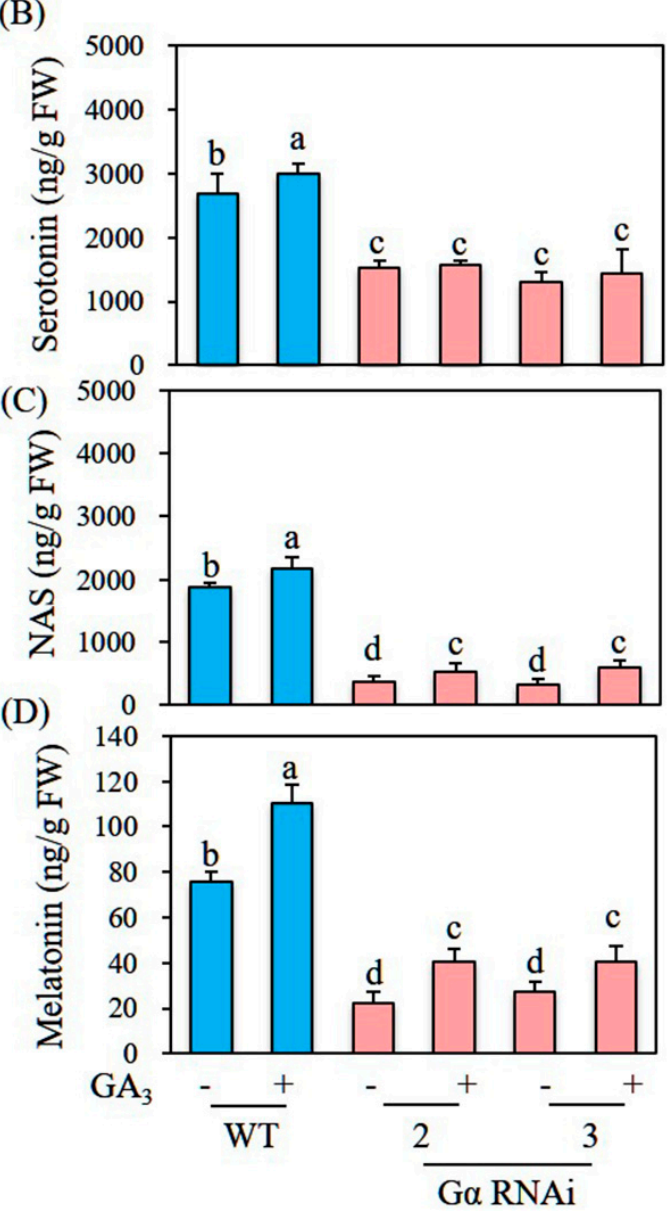

Figure 7. Effect of GA3 in the $G \alpha$ RNAi lines. (A) Seedling phenotypes in response to $\mathrm{GA}_{3}(10 \mu \mathrm{M})$ treatment for $24 \mathrm{~h}$, followed by treatment with $0.5 \mathrm{mM}$ cadmium for 3 days. (B) Serotonin levels after $\mathrm{GA}_{3}$ and cadmium treatment. (C) $N$-Acetylserotonin levels after $\mathrm{GA}_{3}$ and cadmium treatment. (D) Melatonin levels after $\mathrm{GA}_{3}$ and cadmium treatment. Seven-day-old rice seedlings of WT and $\mathrm{T}_{2}$ homozygous $G \alpha$ RNAi lines were used. Data are means of three replicates. Different letters denote significant differences ( $p<0.05$; ANOVA, followed by Tukey's HSD post hoc tests).

\section{Discussion}

Melatonin biosynthesis is initiated from aromatic amino acid tryptophan in four steps catalyzed by tryptophan decarboxylase (TDC), tryptamine 5-hydroxylase (T5H), SNAT, and ASMT [13]. In plants, melatonin synthesis requires light, reactive oxygen species (ROS), and various photoreceptors (e.g., phytochromes and cryptochromes) $[16,23,30]$. Many biotic and abiotic stresses that cause ROS production can contribute to increased melatonin production in plants. Increased melatonin production in response to stresses counteracts the effects of ROS, either by directly scavenging ROS or by inducing an array of antioxidant enzymes (e.g., superoxide dismutase, ascorbate peroxidase, and glutathione S-transferase) [3,31,32]. For example, high light levels induced 38-fold higher melatonin production compared with low light in St. John's wort [33]; a sixfold increase in melatonin synthesis was observed in barley roots in response to $10 \mathrm{mM}$ hydrogen peroxide $\left(\mathrm{H}_{2} \mathrm{O}_{2}\right)$ treatment [34]. Furthermore, bacterial and fungal pathogens induced melatonin synthesis in Arabidopsis [14] and cotton [35], respectively.

Commensurate with melatonin induction in response to many stresses, the adverse effects of these stresses are mitigated by melatonin partly via crosstalk among various endogenous hormones and melatonin, which was presumably acquired during plant evolution after the advent of plant hormones [3]. The effects of melatonin on plant hormone regulation are broad and vary among plant species and stress factors. For example, exoge- 
nous melatonin treatment increased indole-3-acetic acid production in Chinese mustard [36] but decreased this production in Arabidopsis [37]. Contrasting effects of melatonin on other hormones (e.g., ABA and ethylene) were also observed in other plant species [38]. Two recent studies reported important discoveries regarding the inter-relationships of endogenous melatonin with endogenous hormone levels. In the Arabidopsis SNAT2 knockout plant (snat2) showing a delayed flowering phenotype, it was found to decrease the expression of ent-kaurene synthase $(K S)$, a key GA biosynthetic gene; this led to reduced GA levels [17]. In contrast, exogenous melatonin treatment suppressed $K S$ expression, indicating contrasting effects of melatonin in vivo and in vitro. These data suggest that decreased GA levels in Arabidopsis snat 2 are indirectly caused by melatonin [17]. Similar to Arabidopsis snat2, transgenic rice downregulating rice SNAT2 (snat2) exhibited decreased BR levels accompanied by BR-deficient erect leaf and dwarf phenotypes [24]. Because BR regulates GA levels [39], these data showing a GA decrease related to Arabidopsis snat2 and a BR decrease related to rice snat2 suggest that GA is closely associated with melatonin synthesis in plants.

As predicted, GA had a positive effect on melatonin synthesis in rice plants, but the GA induction by melatonin was not observed (Figure 8). Generally, GA promotes growth via cell expansion and division in parallel with many other physiological functions including seed germination, flowering, and photomorphogenesis [40]. In particular, GA orchestrates these functions through the negative transcriptional repressor protein DELLA. GA triggers DELLA degradation, thereby releasing many active functions inhibited by DELLA; conversely, DELLA accumulation in the absence of GA inhibits growth, flowering, seed germination, and skotomorphogenesis, among other effects [40]. GA-mediated DELLA degradation leads to increased ROS, resulting in growth promotion and decreased stress tolerance; DELLA accumulation causes stress tolerance by decreasing ROS. A major question related to GA-induced melatonin synthesis is why GA induces melatonin, while melatonin does not induce GA. GA-induced growth promotion may be vulnerable to many adverse stresses that are counteracted by GA-induced melatonin synthesis because melatonin acts as a potent signaling molecule to protect plants from a diverse array of abiotic and biotic stresses [3]. Regarding the failure of melatonin-induced GA production, exogenous melatonin treatment does not induce $K S$, the key gene for GA synthesis [17]; this observation suggests that melatonin synthesis acts downstream of GA. The reduction of GA in melatonin-deficient Arabidopsis snat2 was ascribed to decreased starch synthesis [4], which eventually led to decreased GA synthesis [41]. The potent inhibitory effects of ABA on melatonin biosynthesis are in sharp contrast to the effects of GA. Both ABA and GA exhibit robust effects on plant growth and development processes including seed germination, stem elongation, flowering, and seed development. However, GA and ABA have antagonistic effects: GA generally promotes these plant processes, while ABA inhibits them [42]. In parallel with the antagonistic effects of GA and ABA on many physiological functions, these two hormones antagonistically regulate melatonin biosynthesis: GA promotes melatonin biosynthesis, while ABA inhibits this process.

To our knowledge, this study is the first to demonstrate that GA can induce melatonin production in rice seedlings and seeds. GA treatment onto mature rice plants grown in the field condition starting at 1 week after flowering affected neither flower development nor other growth parameters such as plant height. The direct involvement of GA in melatonin synthesis was verified by genetic evidence that GA biosynthetic (GA3ox2 RNAi) and signaling mutants ( $G \alpha$ RNAi) result in severe decreases in melatonin production. Melatonin is a well-known health-promoting molecule with potent antioxidant activity that is positively involved in anti-inflammatory, antiaging, innate immunity enhancement, and anticancer activities [43]. GA is also widely used in the agricultural industry to promote crop productivity by inducing seedlessness in fruits (e.g., grapes) or increasing seed germination and fruit production in many plants [42,44]. Our results may contribute to the development of a practical approach for increasing melatonin in rice leaves and seeds 
through exogenous GA treatment; the resulting melatonin-rich seeds and plants may be used as functional foods for their health benefits.

\section{Endogenous elicitors}

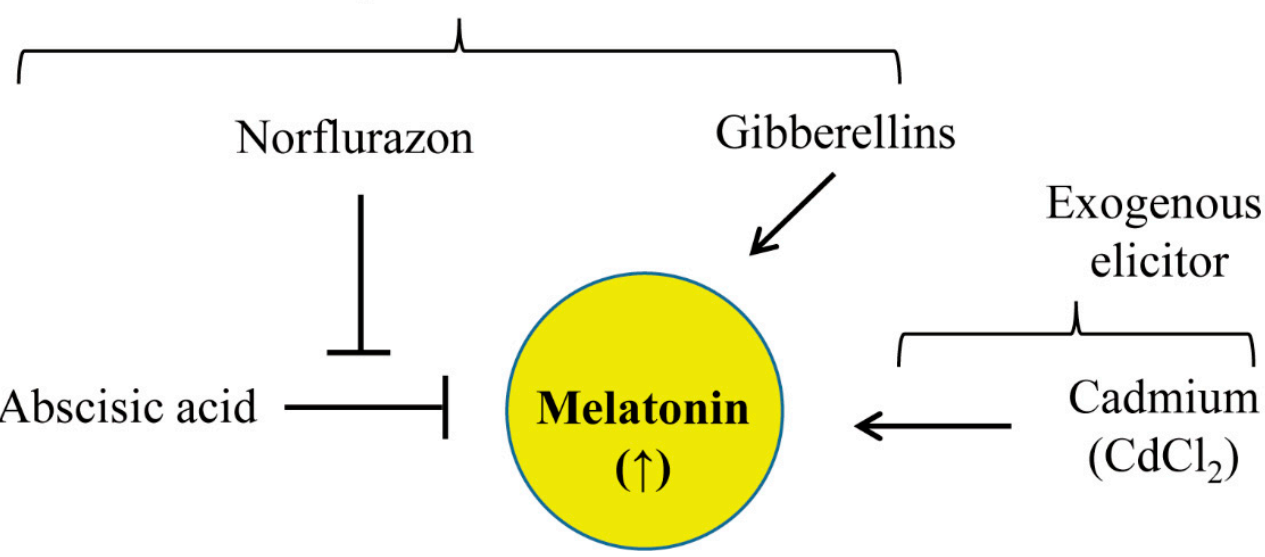

Figure 8. Proposed model of melatonin induction by endogenous hormones. GA induces melatonin production, whereas ABA inhibits melatonin production. Norflurazon, an ABA biosynthetic inhibitor, functions as a potent elicitor of melatonin production.

\section{Conclusions}

In the present study, we reported the mechanistic basis for a practical approach to increase melatonin production in rice leaves and seeds through GA treatment; the resulting melatonin-rich seeds and plants may be used as functional foods for their health benefits. The role of GA as an endogenous elicitor of melatonin synthesis was verified in vivo using transgenic rice plants downregulating GA synthesis and signaling pathway. Transgenic rice plants downregulating GA3ox2 (GA biosynthesis) or G $\alpha$ (signaling) synthesized less melatonin than that of wild-type plants. Our findings imply that plants or seeds with enriched melatonin levels can be produced through exogenous GA treatment under field conditions. These melatonin-rich agricultural products benefit human health through their aging prevention and antioxidant properties.

Author Contributions: Conceptualization, K.B.; investigation, O.J.H. and K.B.; writing-review and editing, O.J.H. and K.B. All authors have read and agreed to the published version of the manuscript.

Funding: This research was supported by grants from the Rural Development Administration (project no. PJ015703012022) and the Basic Science Research Program through the National Research Foundation (NRF-2021R1C1C2006271) of the Republic of Korea.

Institutional Review Board Statement: Not applicable.

Informed Consent Statement: Not applicable.

Data Availability Statement: Data presented in this study are available within the article.

Conflicts of Interest: The authors declare no conflict of interest.

\section{References}

1. Arnao, M.B.; Hernández-Ruiz, J. Melatonin as a regulatory hub of plant hormone levels and action in stress situations. Plant Biol. 2021, 23, 7-19. [CrossRef] [PubMed]

2. Sun, C.; Liu, L.; Wang, L.; Li, B.; Jin, C.; Lin, X. Melatonin: A master regulator of plant development and stress responses. J. Integr. Plant Biol. 2021, 63, 126-145. [CrossRef] [PubMed]

3. Zhao, D.; Wang, H.; Chen, S.; Yu, D.; Reiter, R.J. Phytomelatonin: An emerging regulator of plant biotic stress resistance. Trends Plant Sci. 2021, 26, 70-82. [CrossRef] [PubMed]

4. Lee, H.Y.; Back, K. Melatonin regulates chloroplast protein quality control via a mitogen-activated protein kinase signaling pathway. Antioxidants 2021, 10, 511. [CrossRef] [PubMed] 
5. Shi, H.; Tan, D.X.; Reiter, R.J.; Ye, T.; Yang, F.; Chan, Z. Melatonin induces class A1 heat shock factors (HSFA1s) and their possible involvement of thermotolerance in Arabidopsis. J. Pineal Res. 2015, 58, 335-342. [CrossRef]

6. Zhao, D.; Yu, Y.; Shen, Y.; Liu, Q.; Zhao, Z.; Sharma, R.; Reiter, R.J. Melatonin synthesis and function: Evolutionary history in animals and plants. Front. Endocrinol. 2019, 10, 249. [CrossRef]

7. Wei, J.; Li, D.X.; Zhang, J.R.; Shan, C.; Rengel, Z.; Song, Z.B.; Chen, Q. Phytomelatonin receptor PMTR1-mediated signaling regulates stomatal closure in Arabidopsis thaliana. J. Pineal Res. 2018, 65, e12500. [CrossRef]

8. Lee, H.Y.; Back, K. The phytomelatonin receptor (PMRT1) Arabidopsis Cand2 is not a bona fide G protein-coupled melatonin receptor. Melatonin Res. 2020, 3, 177-186. [CrossRef]

9. Sharif, R.; Xie, C.; Zhang, H.; Arnao, M.B.; Ali, M.; Ali, Q.; Muhammad, I.; Shalmani, A.; Nawaz, M.A.; Chen, P.; et al. Melatonin and its effects on plant systems. Molecules 2018, 23, 2352. [CrossRef]

10. Ye, T.; Hao, Y.H.; Yu, L.; Shi, H.; Reiter, R.J.; Feng, Y.Q. A simple, rapid method for determination of melatonin in plant tissues by UPLC coupled with high resolution orbitrap mass spectrometry. Front. Plant Sci. 2017, 8, 64. [CrossRef]

11. Wei, Y.; Liu, G.; Chang, Y.; Lin, D.; Reiter, R.J.; He, C.; Shi, H. Melatonin biosynthesis enzymes recruit WRKY transcription factors to regulate melatonin accumulation and transcriptional activity on W-box in cassava. J. Pineal Res. 2018, 65, e12487. [CrossRef]

12. Wang, L.F.; Li, T.T.; Zhang, Y.; Guo, J.X.; Lu, K.K.; Liu, W.C. CAND2/PMTR1 is required for melatonin-conferred osmotic stress tolerance in Arabidopsis. Int. J. Mol. Sci. 2021, 22, 4014. [CrossRef] [PubMed]

13. Back, K. Melatonin metabolism, signaling and possible roles in plants. Plant J. 2021, 105, 376-391. [CrossRef] [PubMed]

14. Shi, H.; Qian, Y.; Tan, D.X.; Reiter, R.J.; He, C. Melatonin induces the transcripts of CBF/DREB1s and their involvement in both abiotic and biotic stresses in Arabidopsis. J. Pineal Res. 2015, 59, 334-342. [CrossRef] [PubMed]

15. Moustafa-Farag, M.; Mahmoud, A.; Arnao, M.B.; Sheteiwy, M.S.; Dafea, M.; Soltan, M.; Elkelish, A.; Hasanuzzaman, M.; Ai, S Melatonin-induced water stress tolerance in plants: Recent advances. Antioxidants 2020, 9, 809. [CrossRef] [PubMed]

16. Lee, K.; Choi, G.H.; Back, K. Cadmium-induced melatonin synthesis in rice requires light, hydrogen peroxide, and nitric oxide: Key regulatory roles for tryptophan decarboxylase and caffeic acid O-methyltransferase. J. Pineal Res. 2017, 63, e12441. [CrossRef] [PubMed]

17. Lee, H.Y.; Lee, K.; Back, K. Knockout of Arabidopsis serotonin N-acetyltransferase-2 reduces melatonin levels and delays flowering. Biomolecules 2019, 9, 712. [CrossRef]

18. Wang, Z.; Chen, C.; Xu, Y.; Jiang, R.; Han, Y.; Xu, Z.; Chong, K. A practical vector for efficient knockdown of gene expression in rice (Oryza sativa L.). Plant Mol. Biol. Rep. 2004, 22, 409-417. [CrossRef]

19. Lee, H.J.; Lee, S.B.; Chung, J.S.; Han, S.U.; Han, O.; Guh, J.O.; Jeon, J.S.; An, G.; Back, K. Transgenic rice plants expressing a Bacillus subtilis protoporphyrinogen oxidase gene are resistant to diphenyl ether herbicide oxyfluorfen. Plant Cell Physiol. 2000, 41 , 743-749. [CrossRef]

20. Hwang, O.J.; Back, K. Simultaneous suppression of two distinct serotonin $N$-acetyltransferase isogenes by RNA interference leads to severe decreases in melatonin and accelerated seed deterioration in rice. Biomolecules 2020, 10, 141. [CrossRef]

21. Feldman, L.J.; Sun, P.S. Effects of norflurazon, an inhibitor of carotenogenesis, on abscisic acid and xanthoxin in the caps of gravistimulated maize roots. Physiol. Plant. 1986, 67, 472-476. [CrossRef] [PubMed]

22. Koschmieder, J.; Fehling-Kaschek, M.; Schaub, P.; Ghisla, S.; Brausemann, A.; Timmer, J.; Beyer, P. Plant-type phytoene desaturase: Functional evaluation of structural implications. PLOS ONE 2017, 12, e0187628.

23. Hwang, O.J.; Kang, K.; Back, K. Effects of light quality and phytochrome from on melatonin biosynthesis in rice. Biomolecules 2020, 10, 523. [CrossRef] [PubMed]

24. Hwang, O.J.; Back, K. Melatonin is involved in skotomorphogenesis by regulating brassinosteroid biosynthesis in plants. J. Pineal Res. 2018, 65, e12495. [CrossRef]

25. Sakamoto, T.; Kobayashi, M.; Itoh, H.; Tagiri, A.; Kayano, T.; Tanaka, H.; Iwahori, S.; Matsuoka, M. Expression of a gibberellin 2-oxidase gene around the shoot apex is related to phase transition in rice. Plant Physiol. 2001, 125, 1508-1516. [CrossRef]

26. Itoh, H.; Ueguchi-Tanaka, M.; Sentoku, N.; Kitano, H.; Matsuoka, M.; Kobayashi, K. Cloning and functional analysis of two gibberellin $3 \beta$-hydroxylase genes that are differently expressed during the growth of rice. Proc. Natl. Acad. Sci. USA 2001, 98, 8909-8914. [CrossRef]

27. Kaneko, M.; Itoh, H.; Inukai, Y.; Sakamoto, T.; Ueguchi-Tanaka, M.; Ashikari, M.; Matsuoka, M. Where do gibberellin biosynthesis and gibberellin signaling occur in rice plants? Plant J. 2003, 35, 104-115. [CrossRef]

28. Oki, K.; Inaba, N.; Kitano, H.; Takahashi, S.; Fujisawa, Y.; Kato, H.; Iwasaki, Y. Study of novel $d 1$ alleles, defective mutants of the $\alpha$ subunit of heterotrimeric G-protein in rice. Genes Genet. Syst. 2009, 84, 35-42. [CrossRef]

29. Ueguchi-Tanaka, M.; Fujisawa, Y.; Kobayashi, M.; Ashikari, M.; Iwasaki, Y.; Kitano, H.; Matsuoka, M. Rice dwarf mutant $d 1$, which is defective in the alpha subunit of heterotrimeric $\mathrm{G}$ protein, affects gibberellin signal transduction. Proc. Natl. Acad. Sci. USA 2000, 97, 11638-11643. [CrossRef]

30. Hwang, O.J.; Back, K. Suppression of rice cryptochrome $1 \mathrm{~b}$ decreases both melatonin and expression of brassinosteroid biosynthetic genes resulting in salt tolerance. Molecules 2021, 26, 1075. [CrossRef]

31. Arnao, M.B.; Hernández-Ruiz, J. Melatonin and reactive oxygen and nitrogen species: A model for the plant redox network. Melatonin Res. 2019, 2, 152-168. [CrossRef]

32. Back, K.; Tan, D.X.; Reiter, R.J. Strategies to generate melatonin-enriched transgenic rice to respond to the adverse effects on rice production potentially caused by global warming. Melatonin Res. 2021, 4, 501-506. [CrossRef] 
33. Murch, S.J.; KrishnaRaj, S.; Saxena, P.K. Tryptophan is a precursor for melatonin and serotonin biosynthesis in in vitro regenerated St. John's wort (Hypericum perforatum L. cv. Anthos) plants. Plant Cell Rep. 2000, 19, 698-704. [CrossRef] [PubMed]

34. Arnao, M.B.; Hernández-Ruiz, J. Chemical stress by different agents affects the melatonin content of barley roots. J. Pineal Res. 2009, 46, 295-299. [CrossRef] [PubMed]

35. Li, C.; He, Q.; Zhang, F.; Yu, J.; Li, C.; Zhao, T.; Zhang, Y.; Xie, Q.; Su, B.; Mei, L.; et al. Melatonin enhances cotton immunity to Verticillium wilt via manipulating lignin and gossypol biosynthesis. Plant J. 2019, 100, 784-800. [CrossRef] [PubMed]

36. Chen, Q.; Qi, W.B.; Reiter, R.J.; Wei, W.; Wang, B.M. Exogenously applied melatonin stimulates root growth and raises endogenous indoleacetic acid in roots of etiolated seedlings of Brassica juncea. J. Plant Physiol. 2009, 166, 324-328. [CrossRef]

37. Wang, Q.; An, B.; Wei, Y.; Reiter, R.J.; Shi, H.; Luo, H.; He, C. Melatonin regulates root meristem by repressing auxin synthesis and polar auxin transport in Arabidopsis. Front. Plant Sci. 2016, 7, 1882. [CrossRef]

38. Arnao, M.B.; Hernández-Ruiz, J. Melatonin and its relationship to plant hormones. Ann. Bot. 2018, 121, 195-207. [CrossRef]

39. Unterholzner, S.J.; Rozhon, W.; Papacek, M.; Ciomas, J.; Lange, T.; Kugler, K.G.; Mayer, K.F.; Sieberer, T.; Poppenberger, B. Brassinosteroids are master regulators of gibberellin biosynthesis in Arabidopsis. Plant Cell 2015, 27, 2261-2272. [CrossRef]

40. Hernández-García, J.; Briones-Moreno, A.; Blázquez, M.A. Origin and evolution of gibberellin signaling and metabolism in plants. Semin. Cell Dev. Biol. 2021, 109, 46-54. [CrossRef]

41. Paparelli, E.; Parlanti, S.; Gonzali, S.; Novi, G.; Mariotti, L.; Ceccarelli, N.; van Dongen, J.T.; Kolling, K.; Zeeman, S.C.; Perata, P. Nighttime sugar starvation orchestrates gibberellin biosynthesis and plant growth in Arabidopsis. Plant Cell 2013, 25, 3760-3769. [CrossRef] [PubMed]

42. Razem, F.A.; Baron, K.; Hill, R.D. Turning on gibberellin and abscisic acid signaling. Curr. Opin. Plant Biol. 2006, 9, 454-459. [CrossRef] [PubMed]

43. Cardinali, D.P. Are melatonin doses employed clinically adequate for melatonin-induced cytoprotection? Melatonin Res. 2019, 2, 106-132. [CrossRef]

44. Cheng, C.; Xu, X.; Singer, S.D.; Li, J.; Zhang, H.; Gao, M.; Wang, L.; Song, J.; Wang, X. Effects of GA 3 treatment on seed development and seed-related gene expression in grape. PLoS ONE 2013, 8, e80044. [CrossRef] [PubMed] 